\title{
NURSE MORAL DISENGAGEMENT
}

\section{Roberta Fida}

Department of Psychology, Sapienza University of Rome, Italy

\section{Carlo Tramontano}

Centre for Research in Psychology, Behaviour and Achievement, Coventry University, Coventry, United Kingdom

\section{Marinella Paciello}

Uninettuno Telematic International University, Rome, Italy

\section{Mari Kangasniemi}

Department of Nursing Science, Faculty of Health Sciences, University of Eastern Finland, Kuopio, Finland

\section{Alessandro Sili}

U.O.C. Direzione Infermieristica Policlinico Tor Vergata, Rome, Italy

\section{Andrea Bobbio}

Department of Philosophy, Sociology, Education and Applied Psychology, University of Padua, Italy

\section{Claudio Barbaranelli}

Department of Psychology, Sapienza University of Rome, Italy

Article published in

Fida, R, Tramontano, C, Paciello M., Kangasniemi, M., Sili, A., Bobbio, A., \& Barbaranelli, C., (2015) Nurse Moral Disengagement. Nursing Ethics. (Epub ahead of print) doi: 10.1177/0969733015574924 


\begin{abstract}
Background: Ethics is a founding component of the nursing profession; however, the literature has shown that nurses sometimes find it difficult to constantly adhere to the required ethical standards. There is limited knowledge about the factors that cause a committed nurse to violate the professional code; moral disengagement, originally developed by Bandura, is an essential variable to consider. Research objectives: This study aimed at developing and validating a nursing moral disengagement scale and investigated how moral disengagement is associated with counterproductive and citizenship behaviour at work among nurses. Research design: The research comprised a qualitative study and a quantitative study, combining a cross-validation approach and a structural equation model, to validate and test the scale.
\end{abstract} Participants and research context: Sixty Italian nurses (63\% female) involved in clinical work and enrolled as students in a postgraduate master's programme took part in the qualitative study. The researchers recruited in 2012434 nurses (76\% female) from different hospitals in three Italian cities using a convenience sampling method to take part in the quantitative study. Ethical considerations: All the organisations involved gave ethical approval; all respondents participated on a voluntary basis and did not receive any form of compensation. Findings: The nursing moral disengagement scale comprised a total of 22 items. Results attested the mono-dimensionality of the scale and its good psychometric properties. In addition results highlighted a significant association between moral disengagement and both counterproductive and citizenship behaviours. Discussion: Results showed that nurses sometimes resort to moral disengagement in their daily practice, bypassing moral and ethical codes that would normally prevent them from enacting behaviours that violate their norms and protocols. Conclusion: The nursing moral disengagement scale can complement personnel monitoring and assessment procedures already in place and provide additional information to nursing management for designing 
interventions aimed at increasing compliance with ethical codes by improving the quality of the nurses' work environment.

\section{Keywords}

Moral disengagement, counterproductive work behaviour, citizenship behaviour, validation, stress 


\section{Introduction}

Ethics is an elementary part of nurses' daily work and is a specific field of professional expertise that has been taken into account in conjunction with other competences. ${ }^{1,2}$ Nurses' ethical behaviour is regulated by national guidelines and legislation ${ }^{3,4}$ as well as by national and international ethical $\operatorname{codes}^{5,6}$ that reflect the shared ethical principles of the profession. As a result, nurses' work must comply with high ethical standards; however, several studies have reported nurses' difficulties adhering to these standards, generating moral distress in the nurses themselves. ${ }^{7-10}$ Based on the previous literature, it is well known that rapid changes in the healthcare environment (poor working conditions, contextual stressors, the pressing need for economical effectiveness) may sometimes prevent nurses from providing ideal care. ${ }^{1,11-13}$ Furthermore, ethics-related frustration has been linked to disruptions in work group collaboration at the unit level ${ }^{1}$ and to nurses' job dissatisfaction, stress levels, burnout rates and intention to leave the profession at the individual level. ${ }^{14,15}$ In addition, nurses struggle to keep their working conduct in line with professional code ${ }^{11,16}$; this can be further exacerbated by a working context that poorly supports their efforts toward compliance with ethical standards. ${ }^{1,12,13}$

Little is known about the moral mechanisms that may lead a fully committed nurse violating professional code under stressful conditions. In this study, the researchers will analyse these kinds of negative behaviours within Bandura's moral disengagement (henceforth MD) theoretical framework.

\section{Nurses' moral disengagement}

Bandura's theory of moral disengagement

Albert Bandura (b. 1925) is an American-Canadian psychologist. He developed the social cognitive theory (SCT), which identifies the basic human capacities that allow people 
to learn about the world and themselves and to regulate their behaviours and individual experiences. ${ }^{17}$ In his model, Bandura described self-efficacy beliefs as an individual's beliefs about his or her capabilities of successfully producing expected outcomes. Moreover, in examining the self-regulation of behaviour, he focused his attention on moral functioning, developing a specific theory of moral agency.

Within the framework of moral agency, Bandura ${ }^{18}$ introduced the mechanisms of MD to explain why and how under certain circumstances morally righteous individuals may sometimes act in contradiction with their ethical principles without experiencing any form of guilt or shame. Usually, people rely on internal moral standards that guide their conduct and cause them to refrain from deplorable behaviours that are not in line with their moral and ethical views. However, the constant and binding adhesion to one's own moral standards cannot be taken for granted. In his theory, Bandura ${ }^{18}$ suggested that MD affects the regulation of conduct by deactivating the internal control of moral standards, allowing people to avoid emotional reactions related to specific moral contents. Hence, MD may be considered a cognitive distortion ${ }^{19}$ or a bias through which individuals may view their own transgressive behaviour and its negative consequences in a socially and morally favourable (or at least acceptable) way without necessitating the abandonment of shared personal and social principles - for nurses, their code of ethics.

MD operates through eight mechanisms at four major loci: behaviour, agency, outcome and recipient. ${ }^{20-21}$ The mechanisms are explained in more detail in relation to each locus and via examples related to the nursing context in Figure 1. Overall, the mechanisms operate in the following ways: at the behaviour locus, through a transformation of unacceptable behaviours into moral ones; at the agency locus, by obscuring or diminishing the relationship between actions and consequences; at the outcome locus, by not acknowledging the detrimental effects of misbehaviour and at the recipient locus, by withdrawing empathetic 
and sympathetic feelings for the victims.

Figure 1

MD was originally studied in relation to aggressive behaviour, ${ }^{21,22}$ but its disinhibitory value in facilitating other forms of deviant behaviours has since been highlighted, ${ }^{23-24}$ including counterproductive work behaviours. ${ }^{25-28}$ Overall, these studies have shown that the more people are morally disengaged, the more they violate individual and organisational norms and values. In addition, recent studies highlighted that stressful working conditions and negative emotions experienced in reaction to these circumstances activate MD. ${ }^{27}$

\section{Moral disengagement and nurses}

In the nursing context, Bandura's SCT has largely been applied to studies of selfefficacy. ${ }^{29-32}$ However, to the best of our knowledge, no previous studies have investigated MD in the nursing context and its potentially dramatic consequences among health professionals. Although several measures of MD do exist, it is generally suggested that researchers develop context-specific measures ${ }^{21,27,28,33}$ to better understand MD's role in different situations; hence, the main aim of this paper is to present and validate a scale of nursing MD and to investigate whether and how MD is associated with counterproductive work behaviour (CWB) and citizenship behaviours enacted by nurses in their workplace. To fill this gap, the availability of a valid and reliable assessment tool is a priority.

\section{Aims and hypotheses}

The aims of this study are as follows: 1) to develop and evaluate a new scale to measure nursing MD; 2) to test run the scale to examine nursing MD in an Italian sample and 3) to test its internal validity, reliability and concurrent validity by exploring the impact of 
nursing MD on CWB and on organisational citizenship behaviour (OCB). The findings from previous studies on MD measures indicate that nursing MD will be a one-factor scale (Hypothesis 1). Moreover, the researchers expect nursing MD to be positively associated with CWB (Hypothesis 2) and negatively associated with OCB (Hypothesis 3).

\section{Method}

The study consisted of two phases. The first phase was developing the nursing MD scale; the second phase included testing the nursing scale through Exploratory and Confirmatory Factor Analyses and exploring the impact of MD on both CWB and OCB using a full-Structural Equation Model (Figure 2).

Insert Figure 2 about here

\section{Phase 1: Nursing MD scale development}

Participants, research setting and recruiting. The sample was comprised of 60 nurses (63\% female; no further socio-demographic data were collected from the participants) currently involved in clinical work and enrolled as students in a postgraduate master's programme at the University Tor Vergata of Rome in Italy. As a part of their curriculum, students attended the course 'Work and organisational psychology', taught by one of the researchers running this study. After obtaining permission from the University, in 2012, the researcher presented the aim and content of the study during a session of this course and invited students to participate. All sixty students agreed to participate in the first phase of this study. 
Data collection and procedure. Data for item generation was collected via the brainstorming method. The process was conducted in five steps (Figure 2). The first step was a 20-minute brainstorming session in small groups (students grouped themselves into 10 equal sub-groups). Participants were asked to list and discuss unethical behaviours they had directly enacted and/or witnessed in their workplace. As an outcome of this step, participants produced six lists of CWB. The second step was a participatory discussion with all of the subjects; specifically, the researcher and participants discussed the possible justification strategies (MD) people might use in similar situations to re-frame their conduct. During the third step (a 20-minute brainstorming session), participants were again divided into the same sub-groups with the mandate of associating every CWB they had already identified in the first step with the most plausible justification they could provide in relation to it, according to their experience. Participants produced six lists of justifications associated with CWB. In the fourth step, the researcher categorised all of the information gathered (justification and associated behaviour) on the basis of Bandura's MD mechanisms (Figure 1). The participants mentioned all the mechanisms, the only exception being dehumanisation. Then, the researcher drafted an initial set of 30 items. Finally, in order to check the content validity of the newly developed items, in the fifth step, three additional researchers (one psychologist and two nurses) with a broad expertise in both this research area and in research methodology, revised items to confirm the appropriateness of wording and to check for their adequacy, plausibility, redundancy and relevance in the nursing context. In this phase each researcher rated independently on a scale from 1 (not relevant at all) to 4 (fully relevant) the degree to which each of the thirty item was relevant for the examination of MD in the nursing context.

Data analysis. All of the sub-group brainstorming sessions were documented, reported on paper and scrutinised via content analysis. ${ }^{34}$ During the fourth step, the researcher read the results of the group work sessions (lists) several times in order to completely understand all of 
the material. After this, the researchers identified the content deductively ${ }^{34}$ according to Bandura's MD theory and then created the items by condensing the content. In the fifth step, the researchers independently read the items developed in the previous step several times in order to revise and improve them. In order to examine the inter-rater agreement intra-class correlation coefficient (ICC) was calculated. Specifically the higher ICC values the greater inter-rater agreement, with an ICC estimate of 1 indicating perfect agreement and 0 indicating only random agreement. In line with Cicchetti ${ }^{35}$ ICC values lower than .40 indicate a poor inter-rater agreement, values between .40 and .59 a fair agreement, values between .60 and .74 a good agreement, and finally values between .75 and 1.0 an excellent agreement. In addition Cronbach alpha coefficient was calculated as an additional index for the examination of the inter-rater reliability. The relevance of each item was then computed by averaging the scores given by researchers. Items with relevance score lower than 2.5 (scale central score) were excluded. Finally, the four researchers involved in steps four and five had a discussion to agree on the final version. Data were analysed with SPSS 19.0.

Ethical considerations. Ethical approval was received from the University; all of the participants took part in the study voluntarily and did not receive any form of financial or non-financial compensation. In addition, asking students to discuss their views in small groups with no direct interference from the researcher kept the influence of the teacher's authority under control. The results of the brainstorming sessions were documented on papers that were collected in a box in order to avoid any association between groups and the content they provided.

\section{Results}

Results from the panel of researchers yielded an intra-class correlation coefficient of .83 and a Cronbach alpha coefficient of .83. Items' relevance scores for the initial set of thirty items ranged from 1.5 to 4.0 with 8 items scoring less than 2.5. As a consequence, based on 
the researchers' agreement and relevance score, the number of items was reduced to 22 (see Table 2).

Phase 2: Testing the MD scale

Participants, recruiting and research setting. The sample was comprised of 434 nurses recruited in 2012 from different hospitals in three cities in Italy using a convenience sampling method. Participants were recruited in different clinical units and comprised shift nurses with at least one year of clinical experience. After obtaining organisational permissions at the hospitals, the research team contacted the nurses' coordinators, all of whom agreed to the procedure chosen for data collection. Trained research assistants provided participants with a questionnaire (in a blank envelope) and asked them to fill it in individually and privately. The nurses were expected to return the blank envelope containing the completed questionnaire by the following day.

Instruments. Altogether, three different scales were used:

a) The nurse moral disengagement scale, developed in the first phase of this study, was used to assess MD among nurses. It consisted of 22 items with a five-point response format (ranging from do not agree at all to strongly agree).

b) The counterproductive work behaviour checklist, developed by Spector and colleagues $^{36}$ and adapted in Italian by Barbaranelli and colleagues, ${ }^{37}$ was used to assess how often participants enacted each component of a list of deviant behaviours at work. This was a 27 -item list with a five-point response scale (ranging from never to every day). The scale provided two scores: one related to behaviours that target individuals (CWB-I), e.g. stole something from a person at work, the other related to behaviours that targeted the organisation (CWB-O), e.g. purposely did work incorrectly. The alpha reliability coefficients in this study were 
equal to .91 and .79 , respectively.

c) The organisational citizenship behaviour scale, developed by Podsakoff and colleagues ${ }^{38}$ and adapted in the Italian context by Argentero and colleagues, ${ }^{39}$ was used to assess participants' voluntary supporting behaviour toward colleagues and the organisation as a whole. This is a fifteen-item scale measuring three OCB factors: altruism, e.g. 'I help others who have been absent'; civic virtue, e.g. 'I do my job without constant requests from my boss' and conscientiousness, e.g. 'I attend meetings that are not mandatory but are considered important'. Response options were presented in a five-point format ranging from it does not apply to me at all to it completely applies to me. The alpha reliability coefficients in this study were equal to .87 for altruism, .79 for civic virtue and .86 for conscientiousness.

Data analysis. As a preliminary analysis, the researchers examined the descriptive statistics of the demographic characteristics of the sample and all of the items it included. The variables' normality was ascertained considering both skewness and kurtosis indices. The internal validity of the nurse MD scale was assessed through exploratory and confirmatory factorial analyses. In particular, a cross-validation approach was adopted, randomly splitting the total sample into two sub-groups. Specifically the SPSS random split routine was used to select approximately the $40 \%$ and $60 \%$ of participants. The researchers performed an exploratory factor analysis (EFA) on the first sub-group (sub-sample A) and a confirmatory factor analysis (CFA) in the sub-sample-B. We preferred this slightly unbalanced solution to guarantee more robust results for CFA, implemented in the slightly larger sample. The number of factors to be extracted in the EFA was defined using the following: 1) chi-square $\left(\chi^{2}\right)$, the root mean square error of approximation (RMSEA) and the comparative fit index (CFI) as indices of goodness of fit and 2) the theoretical meaning of the factor. ${ }^{40}$ Confirmatory factor analysis (CFA), in the larger sub-sample-B, was then used to cross- 
validate the most plausible factor structure solution derived from the EFA on sub-sample-A. In line with the literature, ${ }^{41,42}$ the researchers considered the following fit-indices to evaluate the CFA solution: omnibus fit indices such as chi-square $\left(\chi^{2}\right)$, incremental fit indices such as the CFI (values > than .95 indicated a good fit) and the RMSEA (values $<$ than .06 indicated a good fit). Furthermore, the weighted root mean square residual (WRMR; values $\leq 1.0$ indicated a good fit) was considered as a relevant criterion. ${ }^{43}$ Due to the highly skewed distribution, the WLS-MV method for parameter estimation (Weighted least squares parameter estimates with standard errors and a mean- and variance-adjusted chi-square test statistic that use a full weight matrix) was used in the EFA and in the CFA as well as. ${ }^{44,45}$.

The reliability of the MD scale was assessed in terms of internal consistency via an alpha coefficient for the total sample. Finally, the scale's validity was further investigated in the total sample by analysing the concurrent validity of the scale through a full structural equation model (full-SEM). In particular, the researchers examined the impact of MD on both CWB and OCB factors. Due to the high number of items included in the instruments, in the measurement model, MD was defined as a latent variable measured by its items, whereas both CWB and OCB variables were posited as single-indicator latent variables. In these cases, in order to account for measurement error and to obtain more precise estimates of structural parameters, error variance for each single indicator was fixed at one minus the sample reliability estimate of the variable multiplied by its sample variance. ${ }^{46}$ As regards the structural model, MD was considered as an independent variable and both CWB and OCB factors as dependent variables. Also in this case the WLS-MV method for parameter estimation was used, in order to account for the non-normality of the items. The same fit indices (and associated criteria) used to evaluate the results of the CFA were adopted to evaluate the appropriateness of this model. Overall data were analysed with SPSS 19.0 and Mplus 7.1 software $^{45}$. 
Ethical considerations. All of the organisations involved gave their ethical approval (the University and the healthcare organisations); further, all participants gave their informed consent, took part in the study voluntarily and did not receive any form of financial or nonfinancial compensation. In addition, in order to preserve anonymity, participants were asked to place their completed questionnaires in blank envelopes and place them in a ballot box available in a designated area of the unit.

\section{Results}

Sample characteristics

The participants $(\mathrm{N}=434)$ were mainly females $(75.2 \%)$, with a mean age of 38.88 years $(\mathrm{SD}=8.27)$, who have been working as nurses for an average of 16.59 years $(\mathrm{SD}=$ 9.66) and in their current organisations for an average of 13.44 years. They generally worked in either medical/surgical units $(54 \%)$ or critical care units (10\%) in public hospitals (88\%) on a full time basis $(81 \%)$. Most of the participants (58\%) worked between seven and eight hours per day (Table 1).

Insert Table 1 about here

Item descriptive statistics

Nursing MD item descriptive statistics are presented in Table 2. Since MD items have a five-point response format they could be treated as continuous variables. However, since the distribution of the items is far from being perfectly normal (i.e., the majority of the items have skewness and kurtosis indices greater than $|1|)$, one may more prudentially consider the items as at the categorical-ordinal level (being this level compatible with the analytical approach used for the EFA and CFA). Accordingly, in addition to means and 


\section{standard deviations Table 2 presents also medians a central tendency index more compatible with ordinal level data.}

Insert Table 2 about here

Results of EFA and CFA

As noted above, EFA and CFA were conducted using WLS-MV estimator to deal with the non-normality of the observed variables. With regard to the EFA performed on the subsample-A ( $\mathrm{N}=181)$, our results were consistent with a one-factor solution (Hypothesis 1). This EFA solution (see Table 2) fits the data well, with the following fit indices: $\chi^{2}(209, \mathrm{~N}=$ $181)=310.79, \mathrm{p}<.01 ;$ RMSEA $=.052(\mathrm{CI}=.039-.063, \mathrm{p}=.396), \mathrm{CFI}=.93$. The EFA solution also accounted for $51 \%$ of the total variance. All loadings were greater than .48 . Along with the 1-factor solution, also four- and seven-factor solutions were explored (taking into account the number of loci and the number of mechanisms represented in the items), but in these cases, solutions were neither simple nor theoretically meaningful. So all together these results confirmed that the 1-factor solution was the one to be cross-validated with CFA.

CFA performed on the sub-sample- $\mathrm{B}(\mathrm{N}=253)$ confirmed the appropriateness of the 1 -factor solution with an acceptable fit to the data, $\chi^{2}(209, \mathrm{~N}=253)=389.81, \mathrm{p}<.01 ; \mathrm{CFI}=$ $96 ; \mathrm{RMSEA}=.058(\mathrm{CI}=.049-.067), \mathrm{p}=.07 ; \mathrm{WRMR}=1.00$, and with all loadings greater than .46 (Table 2). This solution accounts for $56 \%$ of the total variance.

\section{Internal consistency}

The Cronbach's alpha of the nurse MD was .87. Corrected item scale correlations ranged from .31 to .63 , with a mean of .50 and a standard deviation of .08 .

Concurrent validity: The impact of nursing $M D$ on $C W B$ and $O C B$

The results of the full-SEM on the entire sample supported the role of MD with 
respect to both CWB and OCB factors (Hypotheses 2 and 3). As noted above, the full-SEM was conducted using WLS-MV estimator to deal with the non-normality of the observed variables. The fit of the model attests for a good approximation to the data: $\chi^{2}(312, N=434)$ $=555.38, \mathrm{p}<.01 ; \mathrm{CFI}=.96 ; \mathrm{RMSEA}=.042(\mathrm{CI}=.036-.048), \mathrm{p}=.99 ; \mathrm{WRMR}=1.04 . \mathrm{As}$ shown in Figure 3, the higher the MD, the higher the levels of both CWB-O and CWB-I and the lower the levels of altruism, civic virtue and conscientiousness. Finally, as shown in Table 3, the CWB and OCB dimensions are significantly correlated.

Insert Figure 3 about here

Insert Table 3 about here

\section{Discussion}

The results of this study attest to the validity of the scale of nursing MD and its role in fostering unethical behaviour and hindering altruistic, conscientious and civic behaviour. Overall, this study provides the first evidence that nurses sometimes resort to MD in their stressful day-to-day lives to bypass personal and professional moral and ethical codes that usually prevent them from enacting behaviours that violate their norms and protocols. In line with Hypothesis 1 results from the EFA and CFA attested to the mono-dimensionality of the nursing MD scale. Coherently with previous studies, ${ }^{21,27,33}$ all the items generated, referring to the seven theoretical mechanisms, can be traced to a common dimension that makes people differently inclined to use MD.

Furthermore results of the full-SEM confirmed Hypothesis 2 about the relationship of MD to CWB. Specifically, the more nurses silence their self-regulatory systems, the more 
they behave disruptively against others (colleagues, supervisors, stakeholders) and the organisation itself. Clearly, this is an undesirable outcome, given that CWB is a costly phenomenon $^{47-51}$ and has an impact on organisations in terms of loss of productivity, damage of property, increased turnover and absenteeism, threatening the organisation and its members' well-being as well as threatening patients' safety. ${ }^{52-56}$ Although it would be possible to envisage some situations in which behaviours violating organisational and social norms may in the short term meet some organisational goals and be justified on this premise, in the long term, these behaviours are damaging in terms of costs and organisational survival. ${ }^{57}$

Similarly, results of the full-SEM confirmed our hypotheses about the relationship of MD to OCB (Hypothesis 3). Specifically morally disengaged nurses behave less prosocially, e.g. avoiding helping their colleagues, working only the bare minimum or not attending meetings. This outcome is undesirable as well, given previous findings attesting to the relevance of $\mathrm{OCB}$ at the individual and unit level in terms of positive impact on job performance, social capital and organisational effectiveness and negative impact on turnover (intention and actual) and absenteeism. ${ }^{58-60}$

Overall the nurse MD scale showed adequate psychometric properties and can be considered a valid and reliable measure. This is a important asset for healthcare organisations, given that the study of MD can be relevant in relation to the organisation culture and nursing management

\section{Organisation culture and nursing management}

A plausible negative consequence of MD is linked to the possibility that these individual mechanisms may permeate the organisational culture. Specifically, a 'morally disengaged culture' can spread across an organisation, causing MD to be further socialised, learned, activated and routinised, generating a vicious circle involving individuals, teams and 
the entire organisation. ${ }^{27,57,61,62}$.

More worryingly, this vicious circle can become even more exacerbated, especially in the presence of social and working conditions that undermine shared rules, norms and ethical codes. In the future, it would be relevant to investigate how and to what extent the work environment and organisational policies, practices and culture facilitate the recourse to MD. Hutchinson et al. ${ }^{63}$ turned their attention toward organisational and cultural factors that should be given priority over individual factors; however, a recent meta-analysis on unethical behaviours ${ }^{64}$ highlighted the concurrent contribution of individual, behavioural and organisational factors in determining unethical choices at work. Furthermore, in line with the stressor-emotion model of CWB, it is important to investigate how a stressful work context facilitates recourse to MD, which in turn increases the likelihood of adopting deviant behaviours. Specifically, large patient-to-nurse ratio, inadequate staffing, lack of opportunity to participate in hospital decisions and limited trust in their leaders and in the organisation are all stressful factors influencing nurses' everyday work that should be taken into account.

Notwithstanding, it is important to investigate the role of nurse managers in relation to nurses' MD. Ethical leadership can be an important protective factor for preventing misconduct: ethical leaders promote normatively appropriate conduct through their own personal actions (following procedural and interpersonal justice and practice); specific behaviours (such as flexibility, positive feedback and goal-setting); interpersonal relationships and through influencing two-way communication, reinforcement and decision-making. ${ }^{65,66}$

\section{Limitations}

These findings represent a preliminary examination of the role of MD in relation to unethical behaviours in the healthcare system, and they have some limitations. The MD measure should be validated cross-nationally, since CWBs were selected in accordance with the specific Italian normative and professional codes and may not be fully applicable to other 
countries. Cautions in generalisability are also linked to the purposive sampling procedure adopted in the present study and to the limited socio-demographic information recorded from participants in the first phase of this study. Moreover, since the methodology used in this study was based solely on self-report, one may question the extent to which self-reporting bias (and in particular, the individual tendency to respond in a socially desirable way) influenced the responses about undesirable behaviours such as CWB. However, the questionnaires in phase two were administered anonymously, and there was no possibility of the subject being identified, which may have mitigated some self-reporting bias. That being said, this does not exclude the fact that some self-reporting bias is present in the results, particularly because of unconscious/non-deliberate processes. Spector et al.$^{67}$ demonstrated the convergence between self- and peer-reported measures of CWB. Moreover, the use of instruments with high reliability and demonstrated validity offsets these limitations to some extent. $^{68}$

\section{Conclusion}

Currently, working in nursing and in the healthcare system is challenging. Internationally, organisations in the healthcare sector are stressed by continuous restructuring, a demand for increased attention to valuing the 'bottom line' while sustaining excellence in caring and healing practices ${ }^{69}$ and structural reforms and financial cuts aimed at increasing their efficiency and competing with other hospitals. ${ }^{70,71}$ This situation may result in an unsupportive work environment for nurses, who in turn may struggle to comply with ethical standards. A comprehensive discussion of the complexity working in the healthcare system is far beyond the aim of this paper; however, it must be noted that nurses oftentimes pay the greatest price in terms of exposure to stressors and can end up enacting behaviours that violate their ethical and professional code. Worryingly, the more they can provide a rationale for this conduct, the more likely they are to enact it. This suggests the relevance of the 
availability of a context-specific MD measure for nursing management, above all when considering that previous literature has highlighted that in order to maximise the effectiveness of interventions aimed at reducing misconduct, a comprehensive assessment and a clear definition of the behaviours organisations want to prevent is required. ${ }^{72,73}$

An understanding of MD may inform interventions designed to prevent or counteract $\mathrm{CWB}$, to foster individual and collective ethical commitment and to guarantee the accuracy and adequacy of procedures and standards. In line with Bandura's theory, interventions to reduce MD should include components aimed at increasing workers' internal moral control through mastery, e.g. role-playing in training sessions, or vicarious experience, e.g. critical incident technique to share good practices and to analyse situations positively managed by other colleagues, rather than being limited to reinforcing external control and sanctions. Practically, preventive and corrective activities should be oriented to improve workers' selfregulatory competencies in the moral domain and for when the work context becomes extremely demanding, challenging or transgressive.

\section{References}

1. Miller J. Opportunities and obstacles for good work in nursing. Nursing Ethics 2006; 13(5): 471-487. doi:10.1191/0969733006nej894oa

2. Tadd W, Clarke A, Lloyd L, et al. The value of nurses' codes: European nurses' views. Nursing Ethics 2006; 13(4): 376-393. doi:10.1191/0969733006ne891oa

3. Brecher B. 'What is professional ethics?' Nursing Ethics 2014; 21(2): 239-244. doi:10.1177/0969733013484485.

4. Meulenbergs T, Verpeet E, Schotsmans $\mathrm{P}$ et al. Professional codes in a changing nursing context: literature review. J Adv Nurs 2004; 46(3): 331-336. doi:10.1111/j.13652648.2004.02992.x 
5. ICN - International Council of Nurses. ICN code of ethics for nurses. Geneva, Switzerland, 2012. http://www.icn.ch/about-icn/code-of-ethics-for-nurses/

6. IPASVI. Il codice deontologico dell'infermiere, 2009. Available from:

http://www.ipasvi.it/norme-e-codici/deontologia/il-codice-deontologico.htm

7. DeKeyser Ganz F and Berkovitz K. Surgical nurses' perceptions of ethical dilemmas, moral distress and quality of care. $J$ Adv Nurs 2012; 68(7): 1516-1525. doi:10.1111/j.13652648.2011.05897.x.

8. Oh Y and Gastmans C. Moral distress experienced by nurses: a quantitative literature review. Nursing Ethics 2013. doi:10.1177/0969733013502803.

9. Ulrich C, Taylor C, Soeken K et al. Everyday ethics: ethical issues and stress in nursing practice. J Adv Nurs 2010; 66(11): 2510-2519. doi:10.1111/j.1365-2648.2010.05425.x.

10. Wocial LD and Weaver MT. Development and psychometric testing of a new tool for detecting moral distress: the Moral Distress Thermometer. J Adv Nurs 2013; 69(1), 167174. doi:10.1111/j.1365-2648.2012.06036.x

11. Aitamaa E, Leino-Kilpi H, Puukka P, et al. Ethical problems in nursing management: The role of codes of ethics. Nursing Ethics 2010; 17(4): 469-482. doi:10.1177/0969733010364896

12. Corley M, Minick P, Elswick R, et al. Nurse moral distress and ethical work environment. Nursing Ethics 2005; 12(4): 381-390. doi:10.1191/0969733005ne809oa

13. Maben J, Latter S and Clark J. The sustainability of ideals, values and the nursing mandate: Evidence from a longitudinal qualitative study. Nursing Inquiry 2007; 14(2): 99-113. doi:10.1111/j.1440-1800.2007.00357.x

14. Flinkman M, Leino-Kilpi H and Salanterä S. Nurses' intention to leave the profession: integrative review. J Adv Nurs 2010; 66(7): 1422-1434. doi:10.1111/j.13652648.2010.05322.x. 
15. Flinkman M, Isopahkala-Bouret U and Salanterä S. Young registered nurses' intention to leave the profession and professional turnover in early career: a qualitative case study. ISRN Nursing 2013; 1-12. doi:10.1155/2013/916061

16. Solum E, Slettebø A and Hauge S. Prevention of unethical actions in nursing homes. Nursing Ethics 2008; 15(4): 536-548. doi:10.1177/0969733008090524

17. Authors. Albert Bandura. In: Miller HL (ed) The SAGE Encyclopedia of theory in psychology. Sage Publications, 2016.

18. Bandura A. Mechanisms of Moral Disengagement in Terrorism. In: Reich W (ed) Origins of terrorism: psychologies, ideologies, states of mind. University Press, New York, Cambridge, 1990, pp.161-191.

19. Gibbs JC, Potter GB and Goldstein AP. The EQUIP Program: teaching youth to think and Act responsibly through a peer-helping approach. Research Press, Champaign, IL, 1995. doi:10.1037/0021-9010.87.3.444.

20. Bandura A. Social Cognitive Theory of Moral Thought and Action. In: Kurtines WM and Gewirtz JL (eds.) Handbook of moral behaviour and development, vol. 1. Hillsdale, NJ: Erlbaum, 1991, pp. 45-103.

21. Bandura A, Barbaranelli C, Caprara GV, et al. Mechanism of moral disengagement in the exercise of moral agency. J Pers Soc Psychol 1996; 71(2): 364-374. doi: 10.1037/00223514.71.2.364.

22. Bandura A, Underwood B and Fromson ME. Disinhibition of aggression through diffusion of responsibility and dehumanization of victims. Journal of Research in Personality 1975; 9(4): 253-269. Retrived http://dx.doi.org/10.1016/00926566(75)90001-X.

23. Bandura A. The role of selective moral disengagement in terrorism and counterterrorism. In: Moghaddam FM and Marsella AJ (eds.) Understanding terrorism: psychosocial 
roots, consequences, and interventions. American Psychological Association, Washington, DC, US, 2004, pp.121-150.

24. Bandura A, Caprara GV, Barbaranelli C, et al. Sociocognitive self-regulatory mechanisms governing transgressive behaviour. J Pers Soc Psychol 2001; 80 (1): 125-135. doi:10.1037/0022-3514.80.1.125.

25. Bandura A, Caprara GV and Zsolnai L. Corporate transgressions through moral disengagement. Journal of Human Values 2000; 6: 57-64. doi:10.1177/097168580000600106.

26. Detert JR, Treviño LK and Sweitzer VL. Moral disengagement in ethical decision making: a study of antecedents and outcomes. J Appl Psychol 2008; 93: 374-391. doi: 10.1037/0021-9010.93.2.374.

27. Fida R, Paciello M, Tramontano C, et al. An integrative approach to understanding counterproductive work behavior: the roles of stressors, negative emotion and moral disengagement. Journal of Business Ethics 2014; Advance online publication. 10.1007/s10551-014-2209-5

28. Moore C, Detert JR, Treviño LK, et al. Why employees do bad things: moral disengagement and unethical organizational behaviour. Personnel Psychology 2012; 65(1): 1-48. doi:10.1111/j.1744-6570.2011.01237.x.

29. Ahmed A and Ouzzani, M. Development and assessment of an interactive web-based breastfeeding monitoring system (LACTOR). Maternal And Child Health Journal 2013; 17(5): 809-815. doi:10.1007/s10995-012-1074-z.

30. Brannagan K, Dellinger A, Thomas J, et al. Impact of peer teaching on nursing students: perceptions of learning environment, self-efficacy, and knowledge. Nurse Education Today 2013; 33(11): 1440-1447. doi:10.1016/j.nedt.2012.11.018.

31. Owen R and Wanzer L. Compassion fatigue in military healthcare teams. APN 2014; 28(1): 2-9. doi:10.1016/j.apnu.2013.09.007. 
32. Salanova M, Lorente L, Chambel MJ et al. Linking transformational leadership to nurses' extra-role performance: the mediating role of self-efficacy and work engagement. $J A d v$ Nurs 2011; 67(10): 2256-2266. doi:10.1111/j.1365-2648.2011.05652.x.

33. Caprara GV, Fida R, Vecchione M, et al. Assessing civic moral disengagement: dimensionality and construct validity. Personality and Individual Differences 2009; 47 (5): 504-509. http://dx.doi.org/10.1016/j.paid.2009.04.027.

34. Graneheim U, Lundman B. Qualitative content analysis in nursing research: concepts, procedures and measures to achieve trustworthiness. Nurse Education Today 2004; 24(2): 105-112.

35. Cicchetti DV. Guidelines, criteria, and rules of thumb for evaluating normed and standardized assessment instruments in psychology. Psychological Assessment. 1994; 6(4): 284-290.

36. Spector PE, Fox S, Penney LM, et al. The dimensionality of counterproductivity: are all counterproductive behaviours created equal? Journal of Vocational Behaviour 2006; 68(3): 446-460. doi:10.1016/j.jvb.2005.10.005.

37. Barbaranelli C, Fida R and Gualandri M. Assessing counterproductive work behaviour: a study on the dimensionality Of CWB Checklist. Testing, Psychometrics, Methodology in Applied Psychology 2013; 20(3): 1-15.

38. Podsakoff PM, Mackenzie SB, Moorman RH, et al. Transformational leader behaviours and their effects on followers' trust in leader, satisfaction, and organizational citizenship behaviours. The Leadership Quarterly 1990; 1(2): 107-142. Retrived http://dx.doi.org/10.1016/1048-9843(90)90009-7.

39. Argentero P, Cortese CG and Ferretti M. An evaluation of organizational citizenship behaviour: psychometric characteristics of the Italian version of Podsakoff et al's scale. Testing, Psychometrics, Methodology in Applied Psychology 2008; 15(2): 61-75. 
http://psycnet.apa.org/psycinfo/2008-16332-001.

40. Comrey AL and Lee HB. A first course in factor analysis. Lowrence Erlbaum associates Inc, Broadway, NJ, 1992.

41. Hoyle RH (ed). Structural equation modeling: concepts, issues, and applications. Sage Publications Inc, Thousand Oaks, CA, US, 1991.

42. Tanaka JS. Multifaceted conceptions of fit in structure equation models. In: Bollen KA and Long JS (eds.) Testing structural equation models. Newbury Park, CA: Sage, 1993, pp.136-162.

43. Yu CY. Evaluating cutoff criteria of model fit indices for latent variable models with binary and continuous outcomes. PhD Thesis, University of California, USA, 2002. Retreived http://www.statmodel.com/download/Yudissertation.pdf

44. Flora DB and Curran PJ. An empirical evaluation of alternative methods of estimation for confirmatory factor analysis with ordinal data. Psychological Methods 2004; 9(4): 466491. doi:10.1037/1082-989X.9.4.466.

45. Muthén LK and Muthén BO. Mplus user's guide. Sixth Edition. Los Angeles, CA, 19982014.

46. Bollen KA. Structural equations with latent variables. Wiley, New York, 1989. doi:10.1002/0470011815.b2a13089.

47. Coffin B. Breaking the silence on white collar crime. Risk Management 2003; 50(9): 8.

48. Greenberg J. Employee theft as a reaction to underpayment inequity: the hidden cost of pay cuts. J Appl Psychol 1990; 75(5): 561-568. doi: 10.1037/0021-9010.75.5.561.

49. Mount M, Ilies R and Johnson E. Relationship of personality traits and counterproductive work behaviours: the mediating effects of job satisfaction. Personnel Psychology 2006; 59 (3): 591-622. doi:10.1111/j.1744-6570.2006.00048.x.

50. Murphy KR (1993). Honesty in the workplace. Brooks/Cole, Belmont, CA, 1993. 
51. Vardi Y and Weitz E. Misbehavior in organizations: Theory, research, and management. Lawrence Erlbaum Associates Publishers, Mahwah, NJ, 2004.

52. Bensimon HF. Violence in the workplace. Training and Development Journal 1994; 28: $27-32$.

53. Einarsen SE, Hoel H, Zapf D, et al. (eds.). Bullying and emotional abuse in the workplace. International perspectives in research and practice. Taylor \& Francis, London, 2003.

54. Leblanc M and Kelloway E. Predictors and outcomes of workplace violence and aggression. J Appl Psychol 2002; 87 (3): 444-453. doi:10.1037/0021-9010.87.3.444

55. Penney LM and Spector PE. Job stress, incivility, and counterproductive workplace behaviour (CWB): the moderating role of negative affectivity. Journal of Organizational Behaviour 2005; 26 (5): 777-796. doi:10.1002/job.336

56. Robinson SL and Bennett RJ. A typology of deviant workplace behaviors: A multidimensional scaling study. Academy of Management Journal 1995; 38(2): 555572. doi:10.2307/ 256693.

57. Moore C. Moral disengagement in processes of organizational corruption. Journal of Business Ethics 2008; 80: 129-139. doi:10.1007/s10551-007-9447-8.

58. Bolino MC, Hsiung HH, Harvey J, et al. "Well, I'm tired of tryin'!” Organizational citizenship behavior and citizenship fatigue. J Appl Psychol 2014; Advance online publication. http://dx.doi.org/10.1037/a0037583

59. Organ DW, Podsakoff PM and MacKenzie SB. Organizational citizenship behavior: Its nature, antecedents, and consequences. Thousand Oaks, CA: Sage, 2006.

60. Podsakoff NP, Whiting SW, Podsakoff PM, et al. Individual- and organizational-level consequences of organizational citizenship behaviors: A meta-analysis. J Appl Psychol 2009; 94: 122-141. doi:10.1037/a0013079

61. Farnese ML, Tramontano C, Fida R, et al. Cheating behaviours in academic context: does 
academic moral disengagement matter? Procedia Social and Behavioural Science 2011; 29: 356-365. Retrived http://dx.doi.org/10.1016/j.sbspro.2011.11.250.

62. Gino F and Galinsky A. Vicarious dishonesty: When psychological closeness creates distance from one's moral compass. Organizational Behavior And Human Decision Processes 2012; 119(1): 15-26. doi:10.1016/j.obhdp.2012.03.011

63. Hutchinson M, Wilkes L, Jackson D, et al. Integrating individual, work group and organizational factors: testing a multidimensional model of bullying in the nursing workplace. Journal of Nursing Management 2010; 18(2): 173-181.

64. Kish-Gephart J, Harrison D and Treviño L. Bad apples, bad cases, and bad barrels: Metaanalytic evidence about sources of unethical decisions at work. J Appl Psychol 2010; 95(1): 1-31.

65. Brown ME, Treviño LK and Harrison DA. Ethical leadership: A social learning perspective for construct development and testing. Organizational behavior and human decision processes 2005; 97(2): 117-134

66. Christian $\mathrm{J}$ and Ellis A. The crucial role of turnover intentions in transforming moral disengagement into deviant behavior at work. Journal Of Business Ethics 2014; 119(2): 193-208.

67. Spector PE, Coulter ML, Stockwell HG, et al. Perceived violence climate: A new construct and its relationship to workplace physical violence and verbal aggression, and their potential consequences. Work and Stress 2007; 21 (2): 117-130. doi: $10.1080 / 02678370701410007$.

68. Spector PE. Method variance as an artifact in self-reported affect and perceptions at work: Myth or significant problem? J Appl Psychol 1987; 72: 438-443. doi: 10.1037/00219010.72.3.438. 
69. Fonteyn M. Response to 'Understanding expert thinking in nursing'. Sch Inq Nurs Pract 2000; 14: 223-225.

70. Wong, CA and Cummings GG. The influence of authentic leadership behaviour on trust and work outcomes of health care staff. Journal of Leadership Studies 2009; 3: 6-23.

71. Bobbio A, Bellan M and Manganelli AM. Empowering leadership, perceived organizational support, trust and job burnout for nurses: A study in an Italian general hospital. Health Care Manage Rev 2012; 37: 77-87, doi:10.1097/HMR.0b013e31822242b2.

72. Berry CM, Ones DS and Sackett PR. Interpersonal deviance, organizational deviance, and their common correlates: A review and meta-analysis. J Appl Psychol 2007; 92, 410 424. doi: 10.1037/0021-9010.92.2.410

73. Claybourn M. Relationships between moral disengagement, work characteristics and workplace harassment. Journal Of Business Ethics 2011; 100(2): 283-301. 
Table 1. Sociodemographic Characteristics $(n=434)$.

\begin{tabular}{|c|c|}
\hline Variables & $\mathrm{n}(\%)$ \\
\hline \multicolumn{2}{|l|}{ Gender } \\
\hline Male & $89(20.5)$ \\
\hline Female & $330(76)$ \\
\hline Missing & $15(3.5)$ \\
\hline Age, mean (SD) & $38.8(8.3)$ \\
\hline \multicolumn{2}{|l|}{ Education } \\
\hline Professional nursing degree & $259(59.7)$ \\
\hline University nursing degree & $155(35.7)$ \\
\hline Missing & $20(4.6)$ \\
\hline \multicolumn{2}{|l|}{ Marital Status } \\
\hline Married & $227(52.3)$ \\
\hline Single & $133(30.6)$ \\
\hline Widowed & $5(1.1)$ \\
\hline Divorced & $48(11.1)$ \\
\hline Missing & $21(4.8)$ \\
\hline \multicolumn{2}{|l|}{ Hospital } \\
\hline Public & $381(87.8)$ \\
\hline Private & $26(6.0)$ \\
\hline Missing & $27(6.2)$ \\
\hline \multicolumn{2}{|l|}{ Units } \\
\hline Medical & $138(31.8)$ \\
\hline Surgery & $99(22.8)$ \\
\hline Emergency & $53(12.2)$ \\
\hline Critical care & $45(10.4)$ \\
\hline Pediatric & $10(2.3)$ \\
\hline Missing & $89(20.5)$ \\
\hline \multicolumn{2}{|l|}{ Contract } \\
\hline Full time & $350(80.6)$ \\
\hline Part time & $55(12.7)$ \\
\hline Missing & $29(6.7)$ \\
\hline Working hours of per day, mean (SD) & $7.20(1.18)$ \\
\hline
\end{tabular}


Table 2. MD Item Descriptive Statistics and standardised factor loadings from EFA and CFA.

\begin{tabular}{|c|c|c|c|c|c|c|c|}
\hline & Median & Mean & SD & Skewness & Kurtosis & $\mathrm{EFA}^{\mathrm{a}}$ & $\mathrm{CFA}^{\mathrm{a}}$ \\
\hline $\begin{array}{l}\text { MD 1. Damaging things at work is not very serious if you think about how many } \\
\text { wrong things leadership does }\end{array}$ & 1 & 1.35 & 0.83 & 2.71 & 7.18 & .633 & .684 \\
\hline $\begin{array}{l}\text { MD 2. Even if a lot of supplies go missing every day, it's not the fault of the } \\
\text { person who takes them, but of the organization for not putting any preventive } \\
\text { measures in place. }\end{array}$ & 1 & 1.57 & 0.97 & 1.82 & 2.79 & .583 & .581 \\
\hline $\begin{array}{l}\text { MD 3. It is not a serious matter to enter falsified (changed or never taken) vital } \\
\text { signs into the chart, if the patient appears to be well. }\end{array}$ & 1 & 1.22 & 0.58 & 3.06 & 10.42 & .638 & .841 \\
\hline $\begin{array}{l}\text { MD 4. Failure to administer a medication is not serious, if no harm is done to the } \\
\text { patient. }\end{array}$ & 1 & 1.29 & 0.64 & 2.42 & 6.10 & .692 & .765 \\
\hline $\begin{array}{l}\text { MD 5. There is nothing wrong with having your work area messy or dirty, when } \\
\text { so many others do the same. }\end{array}$ & 1 & 1.14 & 0.50 & 4.29 & 21.63 & .910 & .918 \\
\hline $\begin{array}{l}\text { MD 6. You can't blame a nurse for occasionally not providing care on time, given } \\
\text { the under-staffing of nurses in the hospital }\end{array}$ & 2 & 2.32 & 1.19 & 0.61 & -0.47 & .483 & .503 \\
\hline MD 7. Patients who are too demanding deserve to be inappropriately restrained. & 1 & 1.36 & 0.67 & 1.93 & 3.30 & .476 & .762 \\
\hline $\begin{array}{l}\text { MD 8. It is not serious to dispose of biological waste improperly, if the } \\
\text { organization does not pay enough attention to waste disposal issues. }\end{array}$ & 1 & 1.28 & 0.61 & 2.60 & 7.99 & .591 & .779 \\
\hline $\begin{array}{l}\text { MD 9. It's not serious to delay care until the next shift seeing that everybody else } \\
\text { does it too. }\end{array}$ & 1 & 1.28 & 0.57 & 2.50 & 8.14 & .739 & .786 \\
\hline $\begin{array}{l}\text { MD 10. Updating patients' vital signs in the chart without actually checking them } \\
\text { every single time, is just a way to speed up your work. }\end{array}$ & 1 & 1.18 & 0.55 & 4.05 & 19.46 & .738 & .88 \\
\hline $\begin{array}{l}\text { MD 11. Giving patients a medication dosage higher than prescribed is just a way } \\
\text { to help them to get better faster. }\end{array}$ & 1 & 1.09 & 0.39 & 4.78 & 24.31 & .900 & .954 \\
\hline $\begin{array}{l}\text { MD 12. It is alright to turn off the patients' call bells during the night shift in } \\
\text { order to ensure a quieter night. }\end{array}$ & 1 & 1.15 & 0.46 & 3.42 & 12.36 & .779 & .809 \\
\hline $\begin{array}{l}\text { MD 13. You can't blame a nurse for giving a different drug from the prescribed } \\
\text { one when the drug is not available on the unit. }\end{array}$ & 1 & 1.23 & 0.56 & 2.79 & 8.76 & .631 & .748 \\
\hline $\begin{array}{l}\text { MD } 14 \text {. To be rude to a very demanding patient is not serious if the workload is } \\
\text { very heavy. }\end{array}$ & 1 & 1.22 & 0.55 & 3.06 & 11.10 & .793 & .799 \\
\hline
\end{tabular}


MD 15. Failure to administer a medication is just a distraction/forgetfulness.

MD 16. An employee cannot be blamed for wasting supplies if the organization does nothing to control the wastage.

MD 17. Administering an expired or improperly stored drug is not serious seeing that everybody else does it.

MD 18. It's not serious to not provide some care you are supposed to as it will be done anyway on the next shift.

MD 19. Overly demanding patients deserve to be overly sedated.

MD 20. An employee who signs out a co-worker who needs to leave for personal reasons, should not be disciplined if all his/her co-workers do the same.

MD 21. If a nurse does not administer care in a timely manner, it is the unit

leader's fault for not knowing how to organize staffing.

MD 22. It's not serious if you can, to take longer breaks than allowed on nights seeing that the doctors and everybody else does it.

$\begin{array}{lllllll}\mathbf{1} & 1.28 & 0.56 & 2.00 & 3.81 & .626 & .582 \\ \mathbf{1} & 1.45 & 0.74 & 1.76 & 3.09 & .580 & .596 \\ & & & & & & \\ \mathbf{1} & 1.06 & 0.26 & 4.92 & 26.04 & .675 & .915 \\ & & & & & & \\ \mathbf{1} & 1.21 & 0.51 & 2.67 & 7.33 & .713 & .721 \\ \mathbf{1} & 1.13 & 0.39 & 3.08 & 9.36 & .710 & .728 \\ \mathbf{1} & 1.13 & 0.54 & 5.19 & 29.47 & .604 & .777 \\ \mathbf{1} & 1.38 & 0.68 & 2.17 & 6.08 & .611 & .577 \\ \mathbf{1} & 1.75 & 0.95 & 1.23 & 1.04 & .513 & .455\end{array}$

Note. a: estimates for factor loadings derived from Mplus STDYX completely standardised solution 
Table 3. Pearson's correlation coefficients among dependent variables included in the model presented in Figure 3.

\begin{tabular}{lcccc}
\hline & 1 & 2 & 3 & 4 \\
\hline 1. CWB-O & - & & & - \\
2. CWB-I & $.56^{* *}$ & - & & \\
3. Altruism & $-.33^{* *}$ & $-.32^{* *}$ & - & \\
4. Civic Virtue & $-.40^{* *}$ & $-.30^{* *}$ & $.83^{* *}$ & - \\
5. Conscientiousness & $-.21^{* *}$ & $-.11^{*}$ & $.56^{* *}$ & $.48^{* *}$ \\
\hline
\end{tabular}

Note. $* * p<.01 . * p<.05 . \mathrm{CWB}-\mathrm{O}=$ Counterproductive work behaviours targeting the organisation; CWB-I = Counterproductive work behaviours targeting individual in the organisation 


\begin{tabular}{|c|c|c|c|}
\hline \multirow{5}{*}{$\begin{array}{l}\text { BEHAVIOUR } \\
\text { LOCUS }\end{array}$} & $\begin{array}{l}\text { Moral justification } \\
\text { portraying deviant behaviours as aimed at social } \\
\text { and moral purposes }\end{array}$ & \multirow[t]{2}{*}{$\Rightarrow$} & $\begin{array}{l}\text { It is alright to turn off the patients' call bells during the } \\
\text { night shift in order to ensure a quieter night }\end{array}$ \\
\hline & & & $\mathrm{T}$ \\
\hline & 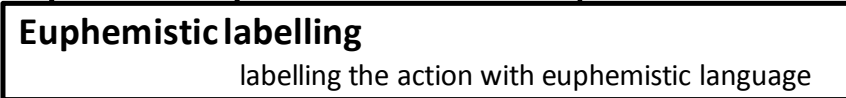 & \multirow[t]{3}{*}{$\Rightarrow$} & $\begin{array}{l}\text { Failure to administer a medication is just a } \\
\text { distraction/forgetfulness }\end{array}$ \\
\hline & $\begin{array}{c}\text { Advantageous comparison } \\
\text { comparing the behaviour with worse and more } \\
\text { flagrantconduct }\end{array}$ & & $\begin{array}{l}\text { Damaging things at work is not very serious if you think } \\
\text { about how many wrong things leadership does }\end{array}$ \\
\hline & & & \\
\hline \multirow{2}{*}{$\begin{array}{l}\text { AGENCY } \\
\text { LOCUS }\end{array}$} & $\begin{array}{l}\text { Displacement of responsibility } \\
\text { considering their behaviour as dictated by social } \\
\text { pressure or by a legitimate authority }\end{array}$ & $\Rightarrow$ & $\begin{array}{l}\text { You can't blame a nurse for occasionally not providing care } \\
\text { on time, given the under-staffing of nurses in the hospital }\end{array}$ \\
\hline & \begin{tabular}{|c|} 
Diffusion of responsibility \\
diffusing the responsibility for a joint action, \\
making individual contribution undistinguishable
\end{tabular} & $\Rightarrow$ & $\begin{array}{l}\text { It's not serious to delay care until the next shift seeing that } \\
\text { everybody else does it too }\end{array}$ \\
\hline \multirow[t]{2}{*}{$\begin{array}{l}\text { OUTCOME } \\
\text { LOCUS }\end{array}$} & \multirow{2}{*}{$\begin{array}{l}\text { Disregarding and distorting } \\
\text { the consequences } \\
\text { misrepresenting the consequences of their } \\
\text { actions }\end{array}$} & \multirow[t]{2}{*}{$\Rightarrow$} & $\begin{array}{l}\text { Failure to administer a medication is not serious, if no } \\
\text { harm is done to the patient }\end{array}$ \\
\hline & & & \\
\hline \multirow{3}{*}{$\begin{array}{l}\text { RECIPIENT } \\
\text { LOCUS }\end{array}$} & $\begin{array}{l}\text { Attribution of blame } \\
\text { considering victims responsible for their } \\
\text { condition, and deserving harm and punishment }\end{array}$ & $\Rightarrow$ & $\begin{array}{l}\text { Patients who are too demanding deserve to be } \\
\text { inappropriately restrained }\end{array}$ \\
\hline & Dehumanization & \multirow{2}{*}{$\Rightarrow$} & \multirow{2}{*}{ Some people deserve to be treated like animals } \\
\hline & zing and dehumanizing them & & \\
\hline
\end{tabular}

Note. All the items provided to illustrate the mechanisms of moral disengagement are selected from the nursing moral disengagement scale. The only exception is the item related to dehumanization that was selected from the scale developed by Bandura and colleagues. ${ }^{21}$

Figure 1. Moral Disengagement: Loci, mechanisms and prototypical items. 


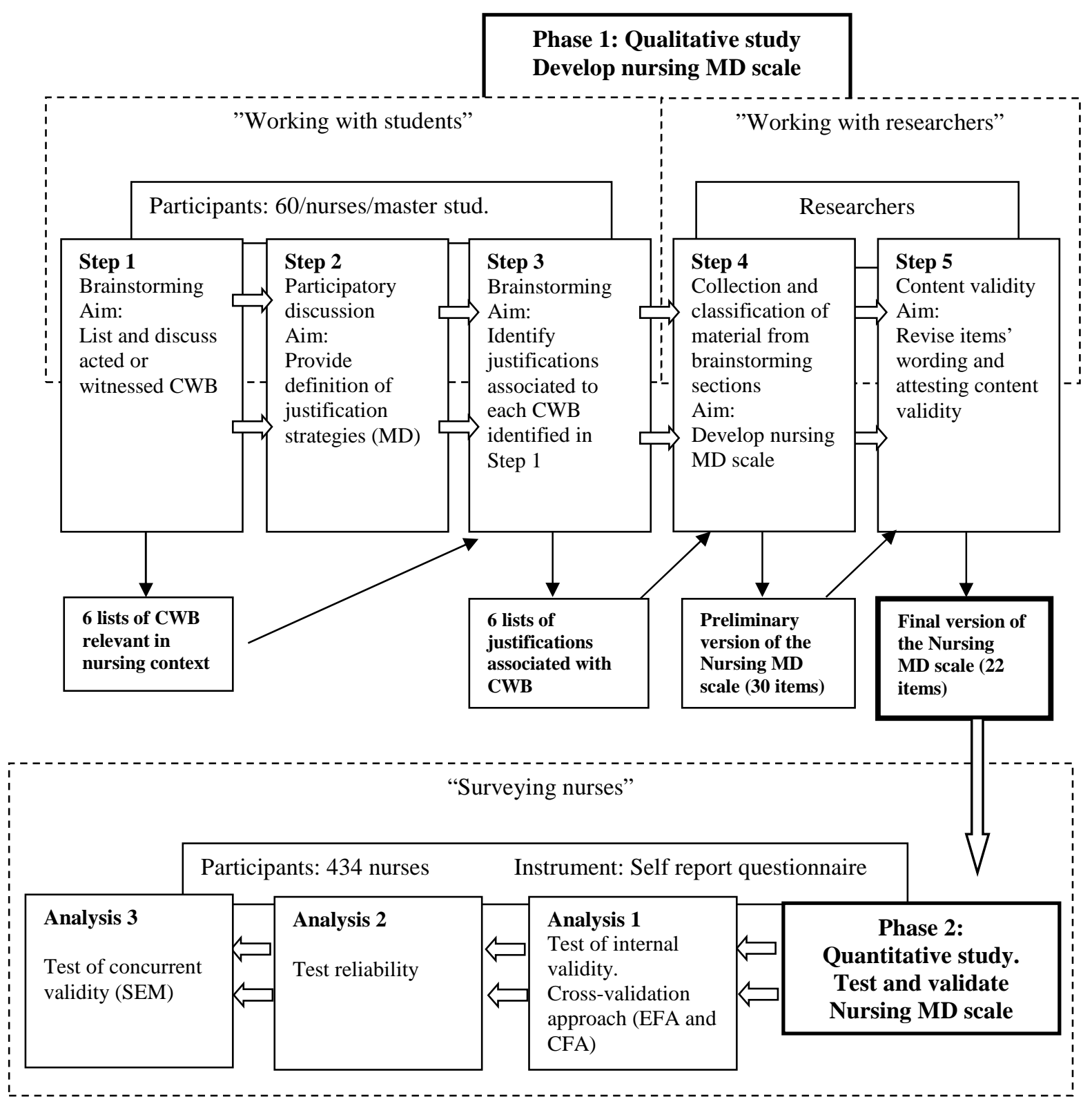

Figure 2. Nursing MD scale development and test process. 


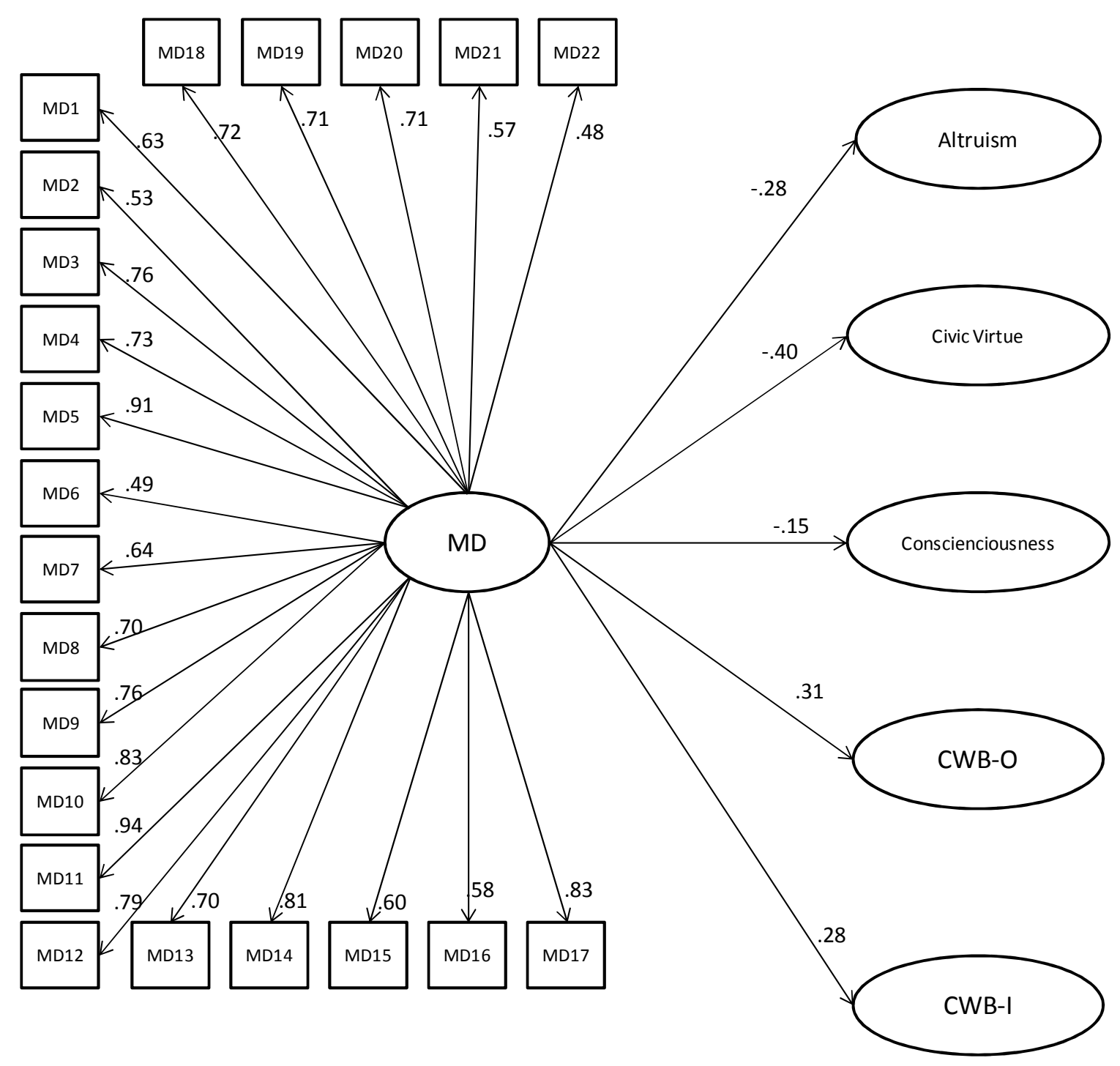

Note. Numbers are standardised regression coefficients

Figure 3. The role of MD in explaining counterproductive and citizenship work behaviours. 